\title{
Cobalt-mediated steroid synthesis
}

\author{
K. Peter C. Vollhardt \\ Department of Chemistry, University of California, Berkeley, California \\ 94720, U.S.A.
}

\begin{abstract}
This lecture will review the current state-of-the-art of cobalt-mediated $[2+2+2]$ cycloadditions in the total synthesis of the steroid nucleus. It will begin with a description of three published approaches. The first relied on the cocyclization of an appropriately 3-substituted 1,5-hexadiyne with bis(trimethylsilyl)ethyne to generate an A-ring aromatic steroid. Three rings and five bonds were made in one step $(D \rightarrow A B C D)$ to provide an intermediate which was converted to $( \pm)$ -estrone. The second route employed an intramolecular cyclization of enediynes to fuse the $B C D$-portion of the Torgov intermediate en route to estrone to an $A-r i n g$ phenol ether $(A \rightarrow A B C D)$. In a third strategy, a variation of the second, the diastereocontrol exerted by a chiral center at the pro-17 position was exploited in the diastereoselective assembly of another $A$-ring aromatic system $(A \rightarrow A B C D)$. Two unpublished approaches to steroids based on this methodology will then be described. The first makes use of an intramolecular $\alpha, \delta, \Omega$-yneenyne cyclization to assemble a pro-vitamin $D$ model system containing a B-ring diene $(D \rightarrow A B C D)$. The second scheme describes a catalytic intramolecular cyclization of an enetriyne which constructs the entire tetracyclic frame from acyclic precusors. This sequence provides an extremely effective total synthesis of $B-r i n g$ aromatic steroids with stereocontrol at the CD-ring junction $(0 \rightarrow A B C D)$. All of these systems have been synthetically connected with naturally occurring steroids or intermediates in their total synthesis.
\end{abstract}

\section{INTRODUCTION}

The chemo-, regio-, and stereoselective construction of carbocycles is one of the major challenges of the synthetic organic chemist. Polycycle construction, particularly of natural products, is of particular interest in this regard, because many natural products and physiologically active compounds have structural features characterized by their presence. Once such class of molecules which has held the traditional attention of synthetic organic chemists are the steroids. So many diverse and frequently ingenious strategies to their molecular framework exist, that the steroids have become a veritable training ground on which to test the synthetic utility of novel synthetic methodology (ref. 1). Pericyclic reactions, in particular the Diels-Alder reaction, have played an important role in these developments (ref. 2). We have opted for an alternative approach, in which polycyclic systems are assembled by inter- and intramolecular [2+2+2]cycloadditions mediated by transition metals, particularly cobalt in the form of $n^{5}$-cyclopentadienylcobalt (ref. 3). This account will review some of the published work involving three total syntheses of the steroid nucleus, and two new approaches which are currently in the developmental stages.

\section{STEROIDS BY THE CATALYTIC COCYCLIZATION OF SUBSTITUTED 1,5-HEXADIYNES WITH ALKYNES}

The first successful cobalt-mediated synthesis of the steroid nucleus was based on the ability of $\mathrm{CpCO}(\mathrm{CO})_{2}$ to cocyclize 1,5-hexadiynes with monoalkynes to provide a versatile entry into the benzocyclobutene nucleus (ref. 4). This approach exploited the ability of benzocyclobutenes to ring open thermally to ortho-xylylenes which are trapped intramolecularly by appended dienophiles (ref. 5) and allowed the rapid assembly of polycyclic compounds. U1timately, 2,3-bis(trimethylsilyl)estratrienone 2 was obtained by reaction of 1 with bis(trimethylsilyl)ethyne (ref. 6). This transformation makes five bonds in one step and fuses the $A B C$ portion of the steroid to the stereospecifically constructed $D$ ring $(D \rightarrow A B C D)$. 

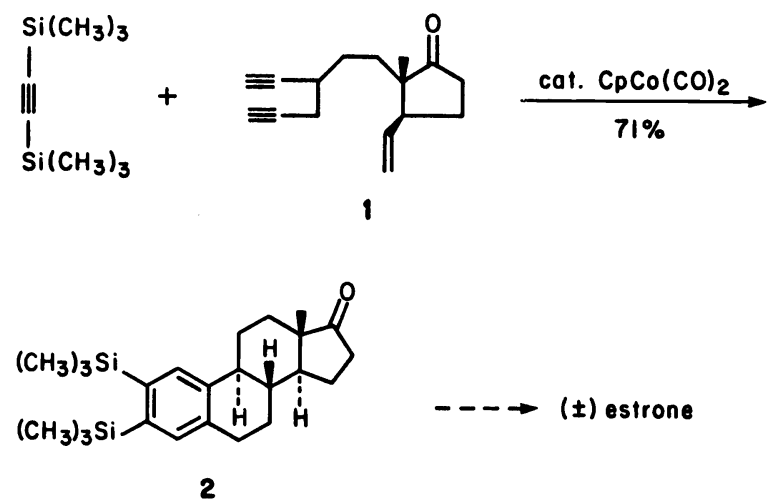

Steroid 2 was taken on to racemic estrone by selective protodesilylation at the 2-position followed by oxidative cleavage of the phenyl-silicon bond. Direct access to phenol ethers of the estrone type was achieved by cocyclization of 1 with alkoxyalkynes (ref. 6). This strategy in steroid synthesis relies on catalytic and not stoichiometric (vide infra) cobalt to fuse the $A B C$ part of the target framework to an already existing $D-r i n g$. Although remarkable diastereoselective, it is not readily amenable to an enantioselective modification. This drawback necessitated the development of a second approach in which a prochiral precursor was cyclized to generate one or more chiral centers in the metal-mediated step.

\section{INTRAMOLECULAR ENEDIYNE CYCLIZATIONS WITH STOICHIOMETRIC COBALT}

In order to enable enantioselective polycycle constructions by our approach, achiral precursors are needed. These were found with enediynes of the type 3 which undergo intramolecular [2+2+2]-cycloadditions in the presence of stoichiometric cobalt to give complexes of the type 4 (ref. 7 ).

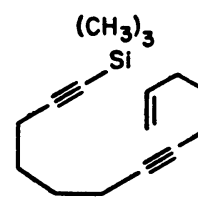

3

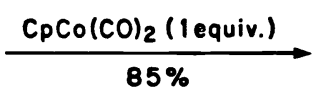<smiles>C[SiH3]C1=C2CCCCC2=C(C(=O)[O-])[C@H]2CCC[C@@H]12</smiles>

4

Surprising diastereoselectivity with respect to the newly formed asymmetric C-13 and the metal is obtainable, boding well for the utilization of chiral and optically active cyclopentandienylcobalt derivatives. The construction of such ligands, either derived from readily available natural products or by total synthesis, is currently under investigation (ref. 8).

The tricyclic framework in 4 may be regarded as the BCD-portion of the steroid nucleus suggesting the approach to their preparation executed in the conversion of 5 to the complexed steroid diene 6 (ref. 9).<smiles>C#Cc1ccc(OC)cc1CCC#CCCC1(C(=C)C)CCCO1</smiles><smiles>CC(=O)OOC(=O)[C@H](C)[Mg]</smiles>

1. $\mathrm{Fe}^{3+}$ 2. $\mathrm{H}^{+}, \mathrm{H}_{2} \mathrm{O}$ $75 \%$<smiles>COc1ccc2c(c1)CCC1=C2CC[C@]2(C)C(=O)CC=C12</smiles> 
The ligand in 6 may be liberated by oxidative demetallation to give a previously unknown (and probably not otherwise accessible) steroid diene. The position of unsaturation in the c-ring is thermodynamically unfavorable relative to the rearranged diene 7 . This compound is a known intermediate in the Torgov synthesis of estrone (ref. 10). The outcome of this approach can be schematized $A \rightarrow A B C D$ (ref. 1)

While this route to the steroid nucleus has the potential for generating optically active steroids through mediation by an optically active catalyst, such a goal may also be achieved by resolution or enantioselective construction of a derivative of 5 with a functionalized, chiral pro-17 center. For this purpose, it was of interest to establish the potential control of asymmetry by this center on conversion of the prochiral vinyl carbon into the c-13 center of the targets.

\section{STEROIDS BY DIASTEREOSELECTIVE CYCLIZATION OF CHIRAL SUBSTRATES}

The potential of a methodology which provides cyclization products in a diastereoselective manner was initially explored with chiral analogs of 3 , namely a series of ethers 8 (ref. 11). Since on cyclization two new elements of chirality are formed (one centered at carbon and one at cobalt) there is the potential for the formation of four stereoisomers 9-12. Interestingly, 9 appears to be the predominant product $\left(\mathrm{R}^{2}=\mathrm{CH}_{3}, \mathrm{C}_{6} \mathrm{H}_{5} \mathrm{CH}_{2}, \mathrm{CH}_{3} \mathrm{OCH}_{2}\right)$, minor amounts of 10 also being detectable. Strangely, when $R^{2}=S i R_{3}$, this selectivity is lost.
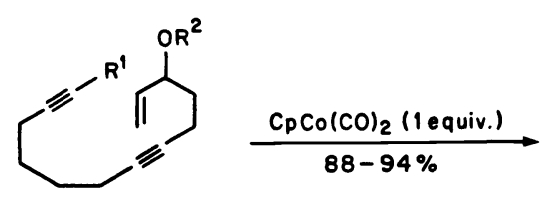

$8\left(R^{1}=S i R_{3}\right)$

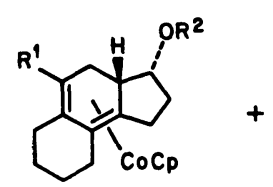

10

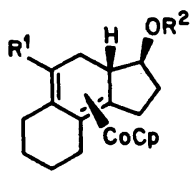

II

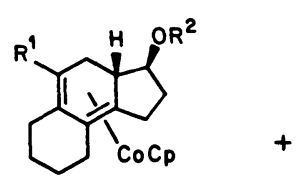

9

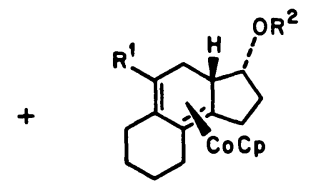

12

These results can be exploited in a diastereoselective steroid synthesis which involves the efficient construction of precursor 13, starting from p-methoxybenzoyl chloride (ref. 11). Gratifyingly, 13 cyclizes as indicated by the model reactions on $\mathbf{8}$ to give predominantly steroid diastereomer 14 , the two D-ring substituents emerging with a strong cis-preference with respect to each other, the metal anti relative to these substituents. $A$ high field proton NMR spectrum of complex 14 is shown in Fig. 1. Its characteristic features include three methyl singlets at $\delta 0.82,3.31$, and 3.39 , a singlet for the cyclopentadienyl hydrogen at 4.41 , and two doublets for the diastereotopic C-ring hydrogens at 0.91 and $2.27 \mathrm{ppm}$. The<smiles>COc1ccc(C(=O)Cl)cc1</smiles><smiles>C=C(C)C(CCC#CCCc1cc(OC)ccc1C#C[SiH3])OCOC</smiles>

13<smiles>COCO[C@H]1CCC2(C)c3ccc(OC)cc3CC[C@@H]12</smiles>

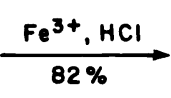

14<smiles>COc1ccc2c(c1)CCC1=C2CC[C@@]2(C)C1=CC[C@H]2O</smiles>

15 
broad peak $\delta 0.33$ is due to the trimethylsilyl group which is suffering from hindered rotation due to the extremely crowded environment in the bay region of the molecule. At $-35^{\circ} \mathrm{C}$ the broad peak separates into three singlets, whereas at $80^{\circ} \mathrm{C}$ coalescence occurs to the usual single line. Compound 14 appears to be the first case of a molecule to exhibit hind-

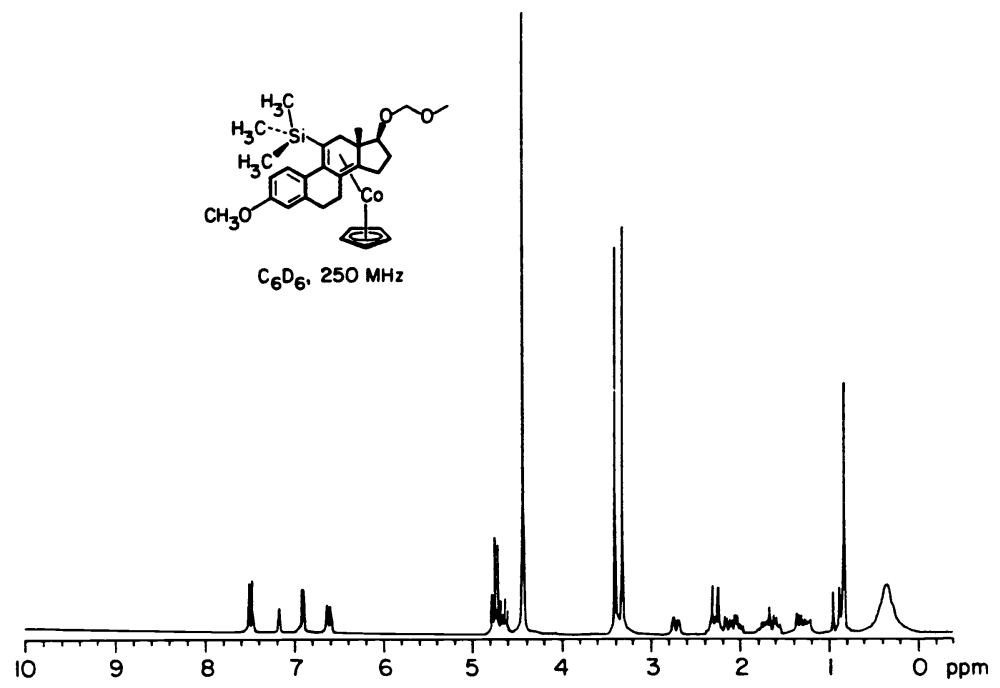

Fig. 1. NMR spectrum of 14 .

ered rotation of a vinyl trimethylsilane moiety $\left(\Delta H^{\prime} \neq 18.8 \mathrm{kcal} \mathrm{mol}^{-1}, \Delta \mathrm{S}^{\prime}=6.7 \mathrm{eu}\right)$. This molecule can be correlated readily with the known steroid 15 by oxidative demetallation under acidic conditions. Under basic conditions the free ligand in 14 is obtained, more stable than that originating from 6 . These compounds promise to be useful intermediates in the construction of new steroid molecules with an elaborated of D-ring.

\section{YNEENYNE CYCLIZATIONS: AN APPROACH TO THE PRO-VITAMIN D NUCLEUS}

The cyclization of 3 to give the tricyclic diene 4 can be modified to precursors with internal double bonds. Thus, for example, yneenyne 16 containing a stereochemically defined double bond undergoes cycloaddition with complete diastereoselectivity to afford complex 17 (ref. 12). Similarly, 18 furnishes the hydrophenanthrene 19, containing two adjacent quaternary centers (ref. 12).

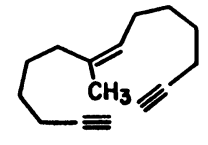

16

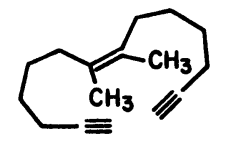

18
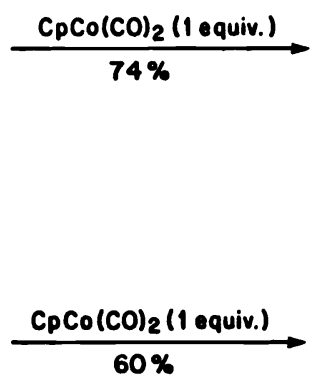

$60 \%$

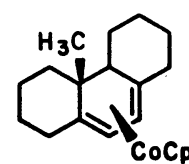

17

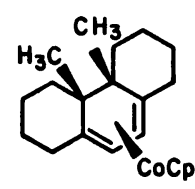

19

Compound 17 may be regarded as a model for the $A B C$ portion of the pro-vitamin $D$ nucleus present in the ligand of 20 , in principle derivable by the retrosynthetic analysis shown in $20 \rightarrow 21$. The latter may in turn be thought of as being constructible by coupling vinyl iodide 22 with the functionalized cyclopentanone ketal 23. Although the goal of synthesizing 21 has not yet been reached, encouraging progress has been made. These studies are important in view of the renewed and increasing interest in vitamin $D$ and its metabolites (ref. 14). 


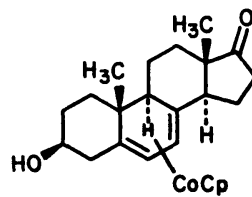

20

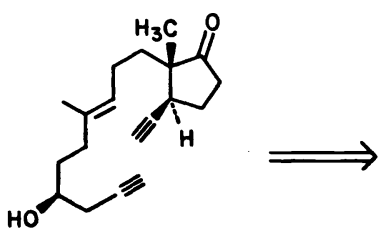

21<smiles>[3H]C=C(C)CCC(O)C=C</smiles><smiles>[X]CC[C@]1(C)[C@@H](C=C[Si](C)(C)C)CC[C@]12CCC(C)(C)CO2</smiles>

A synthetic approach to 22 [R=THP] begins with 4-pentyn-1-ol (24). The stereochemistry of the double bond was elaborated by carbozirconation-iodination providing first 25 (ref. 15). The remainder of the molecule was assembled by standard synthetic methodology.

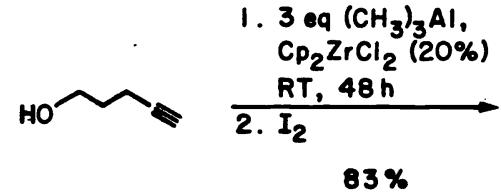

24

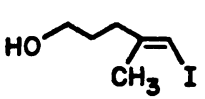

25
1. CIIII

$\mathrm{CH}_{2} \mathrm{Cl}_{2},-50^{\circ} \mathrm{C}, 95 \%$

2. $\mathrm{E}-\mathrm{CH}_{2} \mathrm{MgBr}$, THF, $-30^{\circ} \mathrm{C}$

3. 1 eq BuMgBr

4. 4 eq $\left(\mathrm{CH}_{3}\right)_{3} \mathrm{SiCl}$, $74 \%$<smiles>[3H]C=C(C)CCC(CC[SiH2]C)OP</smiles>

22

The preparation of derivatives of the type 23, namely ethynylcyclopentanone ketals 26 and 27 , occurs in good yield as shown in the scheme starting with 2-methylcyclopent-2-enone.

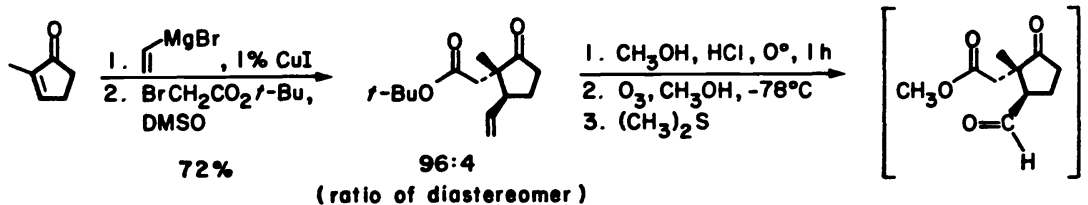
(rotio of diastereomer)

1. $\mathrm{HO} \times \mathrm{OH}$.

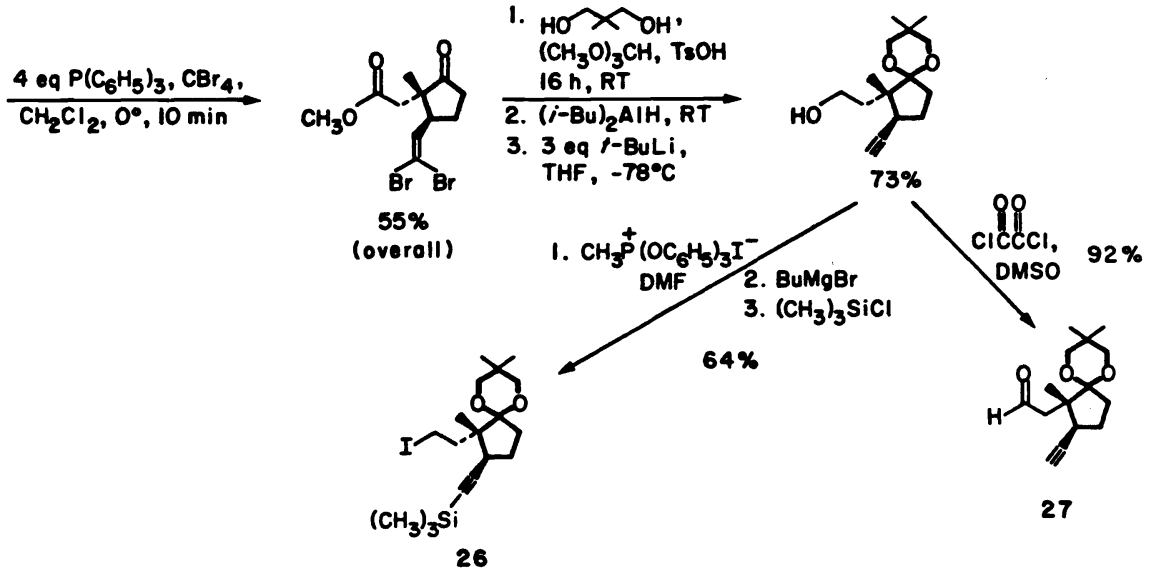

While attempts are underway to couple 22 and 26 to give the desired intermediate of the type 21 , a model study has been executed involving enyne 28 . Lithiation, followed by coupling with 27, gave the two diastereomeric allylic alcohols 29 and 30 in equal amounts, but separable by silica gel chromatography. Diastereomer 29 was protected as the methyl ether, protodesilylated, and cyclized with stoichiometric cobalt. At the present stage the final 
cyclization product is obtained in only low yield and the stereochemistry at C-13 is uncertain. It appears that the presence of an allylic oxygen function in the precursor yneen-

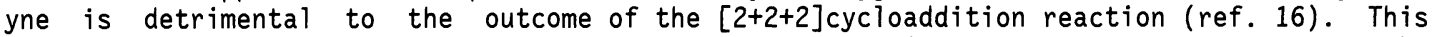
problem may possibly be circumvented by employing alternative precursors. In any event, the production of 31 is the first to generate a B-ring diene in a new $D \rightarrow A B C D$ approach.

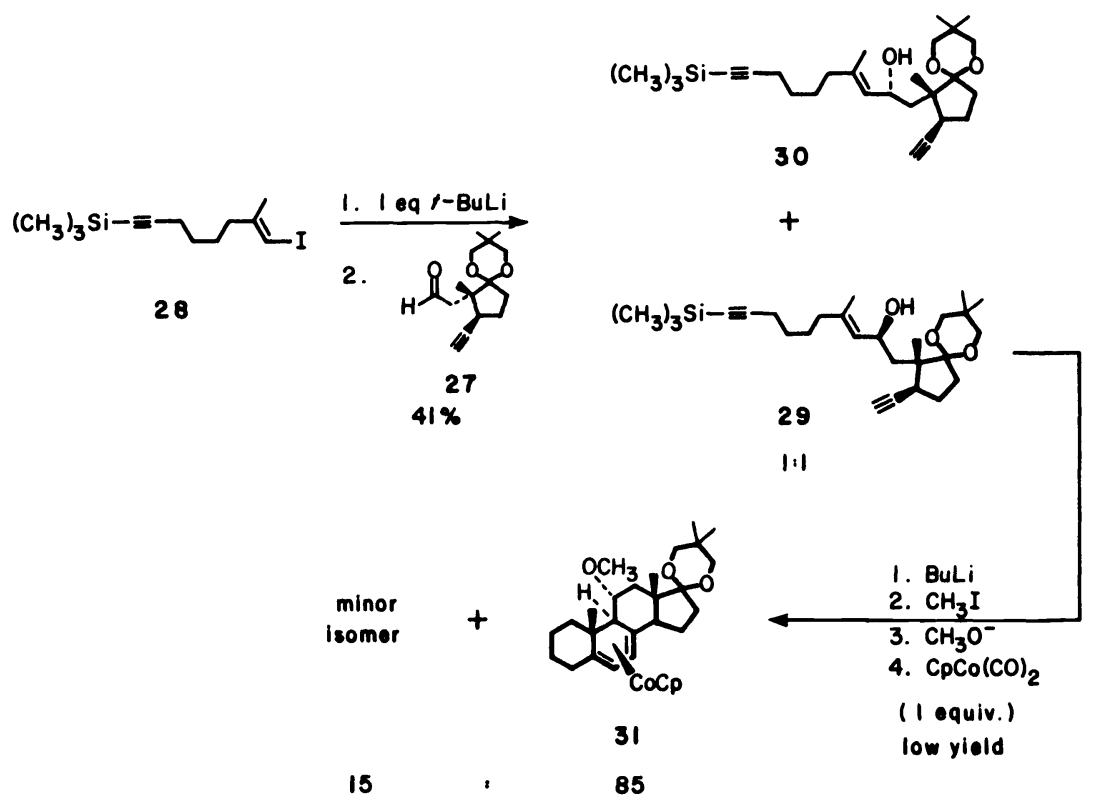

\section{CATALYTIC INTRAMOLECULAR CYCLIZATION OF A COMPLETELY ACYCLIC ENETRIYNE: THE ONE STEP ASSEMBLY OF ALL FOUR RINGS}

While the cobalt-mediated approaches to the steroid nucleus described so far construct three rings in one step to be fused to an already existing A- or D-ring, none of them achieve the type of polycyclization accomplished in biomimetic schemes (ref. 17) in which all rings of the steroid framework are made in one step. How could one design the $[2+2+2]$ cycloaddition strategy to incorporate such a feature? The retrosynthetic analys is $32 \rightarrow$ $33 \rightarrow 34$ reveals that such a scheme might be possible for the preparation of the rare class of B-ring aromatic steroids (ref. 18).<smiles></smiles>

A convergent assembly of the requisite enetriyne starting material originating from 1-trimethylsilyl-1,5-hexadiyne 35 relies on its regioselective metallation at the 3 - and 6-positions (ref. 19), followed by equally selective sequential alkylation to give 36 . This material is then converted readily to 34. Various other enetriynes can be made by modifications of this sequence.

The diol 34, and some of its derivatives, including those in the ethyl series 39 , can be cyclized in the presence of catalytic cobalt to provide an efficient entry into the class of B-ring aromatic steroids as exemplified by the synthesis of 37,38 , and 40 . It will be noted that the intramolecular Diels-Alder reaction (e.g. 33 $\rightarrow 32$ ) is stereospecific furnish- 
I. 2 BuLI,TMEDA
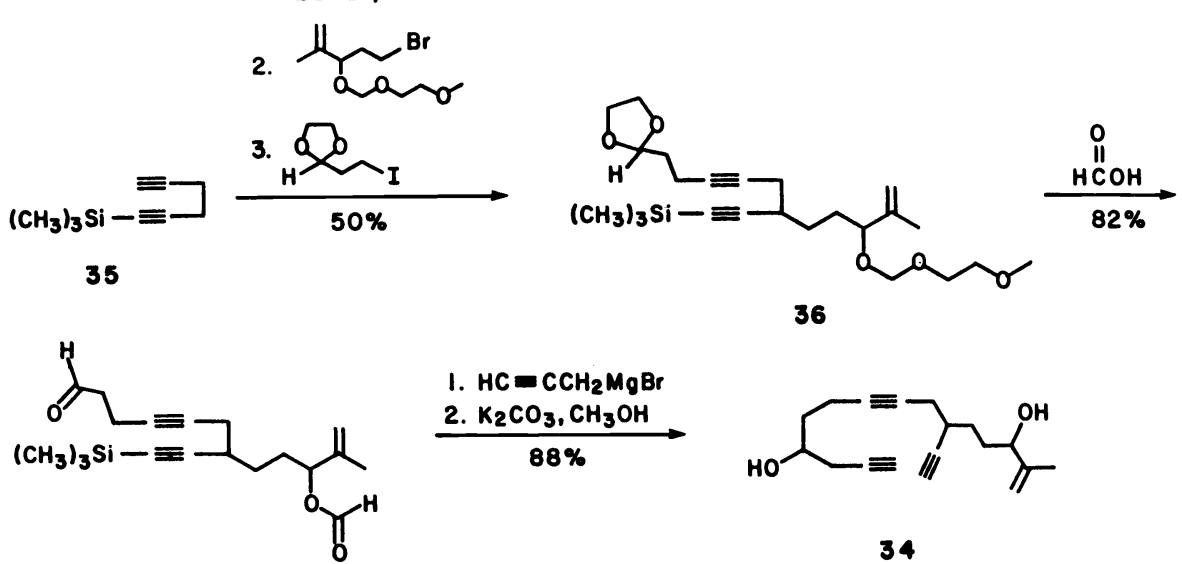

I. $\mathrm{HC}=\mathrm{CCH}_{2} \mathrm{MgBr}$

2. $\mathrm{K}_{2} \mathrm{CO}_{3}, \mathrm{CH}_{3} \mathrm{OH}$

$88 \%$<smiles>C#CCC(O)CCC#CCC(C#C)CCC(O)C(=C)C</smiles>

34

ing the desired trans-C,D-ring junction. These molecules can be correlated with the natural products or other known systems by standard synthetic manipulations (ref. 18, 20). The strategy inherent in these transformations may be designated $0 \rightarrow A B C D$.<smiles>C#CCC(O)CCC#CCC(C)CCC(O)C(=C)C</smiles><smiles>CCCCOC(=O)OC(C)(C)C</smiles><smiles></smiles><smiles>C#CCC(CCC#CCC(C#C)CCC(OC)C(=C)C)OC</smiles>

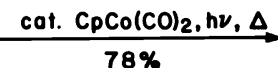<smiles>COC1CCc2c(ccc3c2CC[C@]2(C)[C@H]3CCC2(C)OC)C1</smiles>

38<smiles>C#CCC(O)CCC#CCC(C)CCC(OC)C(=C)CC</smiles>

cot. $C_{p} C_{0}\left(\mathrm{CO}_{2}, h \nu, \Delta\right.$ $92 \%$<smiles>CCC12CCc3c(cccc31)CC[C@]2(O)CC</smiles>

\section{CONCLUSION}

This article has summarized the current state-of-the-art of our synthetic methodology employing catalytic or stoichiometric cobalt in the cyclization of alkenynes to provide the steroid framework. These transformations, which can be carried out both intra- as well as intermolecularly, generate a minimum of three rings in one step with generally excellent chemo-, regio-, and stereoselectivity. In order to improve this strategy further, even more convergent schemes for cyclization will have to be found. These approaches will rely on the increasing delineation of the chemoselectivity of the cyclization when various unsaturated moieties are allowed to react in an intermolecular sense.

\section{ACKNOWLEDGEMENT}

This work was supported by the National Institutes of Health (GM-22479). The author is a Miller Professor in residence, 1985-1986.

\section{REFERENCES}

1. A.A. Akhrem and Y.A. Titov, Total Steroid Synthesis, Plenum Press, New York (1970); R.T. Blickenstaff, A.C. Ghosh and G.C. Wolf, Total Synthesis of Steroids, Academic Press, New York (1974).

2. G. Desimoni, G. Tacconi, A. Barco and G.P. Pollini, Natural Products Synthesis Through Pericyclic Reactions, American Chemical Society, Washington, D.C. (1983). 
3. a. K.P.C. Vollhardt, Angew. Chem. 96, 525 (1984); Angew. Chem., Int. Ed. Eng1. 23,539 (1984). b. K.P.C. Vollhardt in T. Lindberg, Ed., Strategies and Tactics in Organic Synthesis, p. 229, Academic Press, New York (1984). c. K.P.C. Vollhardt in H. Grünewald, Ed., Chemistry for the Future, p. 181, Pergamon Press, New York (1984).

4. K.P.C. Vollhardt, Acc. Chem. Res. 10, 1 (1977).

5. G. Quinkert and H. Stark, Angew. Chem. 95, 651 (1983); Angew. Chem., Int. Ed. Engl. 22, 637 (1983); R.L. Funk and K.P.C. Vollhardt, Chem. Soc. Rev. 9, 41 (1980); T. Kametani, Pure Appl. Chem. 51, 747 (1979); W. Oppolzer, Angew. Chem. 89, 10 (1977); Angew. Chem., Int. Ed. Engl. 16, 10 (1977); Synthes is 793 (1978); T. Kametani and K. Fukumoto, Heterocycles 8,519 (1977); T. Kametani and H. Nemoto Tetrahedron $\underline{37}, 3$ (1981).

6. R.L. Funk and K.P.C. Vollhardt, J. Am. Chem. Soc. 102, 5245, 5253 (1980).

7. E.D. Sternberg and K.P.C. Vollhardt, J. Am. Chem. Soc. 102, 4839 (1980); J. Org. Chem. 49,1564 (1984).

8. R.L. Halterman and K.P.C. Vollhardt, submitted for publication.

9. E.D. Sternberg and K.P.C. Vollhardt J. Org. Chem. 47, 3447 (1982); 49, 1574 (1984).

10. S.N. Ananchenko and I.V. Torgov, Tetrahedron Lett. 1553 (1963); A.V. Zakharychev, S.N. Ananchenko, I.V. Torgov, Steroids 4, 31 (1964); G.H. Douglas, J.M. Graves, G.A. Hughes, B.J. McLoughlin, J. Siddall and H. Smith J. Chem. Soc. 5073 (1963)

11. J.-C. Clinet, E. Duñach and K.P.C. Vollhardt, J. Am. Chem. Soc. 105, $6710(1983)$ and unpublished results.

12. T.R. Gadek and K.P.C. Vollhardt, Angew. Chem. 93, 801 (1981); Angew. Chem., Int. Ed. Engl. 20, 802 (1981).

13. M. Malacria and K.P.C. Vollhardt, J. Org. Chem. 49, 5010 (1984).

14. S. Yamada, K. Nakayama, H. Takyama, T. Shinki and T. Suda, Tetrahedron Lett. 25,3239 (1984); S.R. Wilson and M.S. Haque, Ibid. 25, 3147 (1984); S.R. Wilson, M.S. Haque, A.M. Venkatesan and P.A. Zucker, Ibid. $\frac{25}{5}, 3 \frac{15}{15}$ (1984); W.H. Okamura, Acc. Chem. Res. 16, 81 (1983); K.S. Kyler and D.S. Watt, J. Am. Chem. Soc. 105, 619 (1983); B. Lythgoe, Chem. Soc. Rev. 9, 449 (1980); see al so Chem. Eng. News 41 (1985).

15. E.-I. Negish i, Pure Appl. Chem. 53, 2333 (1981).

16. T.R. Gadek and K.P.C. Vollhardt, unpublished.

17. For a review, see: P.A. Bartlett in J.D. Morrison, Ed. Asymmetric Synthesis, Vol. 3, p. 341, Academic Press, New York (1984).

18. N.S. Narasimhan and C.B. Bapat, J. Chem. Soc., Perkin Trans. I 1435 (1984); M.L. Mihailovic, J. Forsek and L. Lorenc, Ibid. 1 (1982); K. Junghans, G.-A. Hoyer and G. Cleve, Chem. Ber. 112, 2631 (1979); P. Kocovsky and Z. Prochazka, Collect. Czechoslov. Chem. Commun. 39, 1905 (1974); G. Kruger, J. Org. Chem. 33, 1750 (1968); C. Djerassi, Ed. Steroid Reactions, Holden-Day, San Francisco (1963).

19. R.L. Halterman, N.H. Nguyen and K. Peter C. Vollhardt, J. Am. Chem. Soc. 107, 1379 (1985).

20. S.H. Lecker, N.H. Nguyen and K.P.C. Vollhardt, submitted for publication. 